\title{
School students' knowledge and understanding of the Global Solar Ultraviolet Index
}

\author{
C Y Wright,${ }^{1,2} \mathrm{PhD} ;$ A I Reeder, ${ }^{3} \mathrm{PhD} ;$ P N Albers, ${ }^{1} \mathrm{MSc}$ \\ ${ }^{1}$ Environment and Health Research Unit, South African Medical Research Council, Pretoria, South Africa \\ ${ }^{2}$ Department of Geography, Geoinformatics and Meteorology, Faculty of Science, University of Pretoria, South Africa \\ ${ }^{3}$ Cancer Society Social and Behavioural Research Unit, Department of Preventive and Social Medicine, Dunedin School of Medicine, \\ University of Otago, Dunedin, New Zealand
}

Corresponding author: CY Wright (cwright@mrc.ac.za)

\begin{abstract}
Background. The Global Solar Ultraviolet Index (UVI) is a health communication tool used to inform the public about the health risks of excess solar UV radiation and encourage appropriate sun-protection behaviour. Knowledge and understanding of the UVI has been evaluated among adult populations but not among school students.

Objectives. To draw on previously unpublished data from two school-based studies, one in New Zealand (NZ) and the other in South Africa (SA), to investigate and compare students' knowledge of the UVI and, where possible, report their understanding of UVI.

Methods. Cross-sectional samples of schoolchildren in two countries answered questions on whether they had seen or heard of the UVI and questions aimed at probing their understanding of this measure.

Results. Self-report questionnaires were completed by 1177 students, comprising 472 NZ (264 year 8 (Y8), 214 year 4 (Y4) students) and 705 SA grade 7 primary-school students aged 8 - 13 years. More than half of the NZ Y8 students answered that they had previously heard about or seen the UVI, whereas significantly more SA students and NZ Y4 students replied that they had neither seen nor heard about the UVI. Among the NZ students who had seen or heard of the UVI, understanding of the tool was fairly good.

Conclusion. The observed lack of awareness among many students in both countries provides an opportunity to introduce an innovative and age-appropriate UVI communication method that combines level of risk with behavioural responses to UVI categories and focus on personal relevance to the UVI message.
\end{abstract}

S Afr Med J 2015;105(12):1024-1029. DOI: 10.7196/SAMJ.2015.v105i12.10120

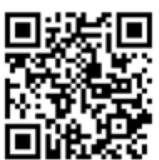

Exposure to solar ultraviolet radiation (UVR) during childhood and adolescence is a key risk factor for the subsequent development of malignant melanoma skin cancer $^{[1]}$ and possibly for some non-melanoma skin cancers. ${ }^{[2]}$ The incidence of melanoma is high in several countries, but especially in Australia and New Zealand (NZ), ${ }^{[3]}$ and among the white population group of South Africa (SA) ${ }^{[4]}$ Public health awareness campaigns that communicate the dangers of excess sun exposure, as recommended by the World Health Organization (WHO), have been ongoing at varying intensities. As part of these efforts, in both $\mathrm{NZ}^{[5]}$ and SA (personal communication, G Coetzee, South African Weather Service, Pretoria) the Global Solar Ultraviolet Index (UVI) has been broadcast in the media for varying periods of time.

The UVI is an international standard measurement of the intensity of solar UVR at the earth's surface and was developed through an international effort by the WHO in collaboration with the World Meteorological Organisation, the United Nations Environment Programme and the International Commission on Non-Ionising Radiation Protection (ICNIRP) ${ }^{[6]}$ The higher the numerical value of the UVI, the greater the intensity of solar UVR and the greater the potential for damage to human health from excess exposure. The UVI is promoted as an education tool to be incorporated into programmes that inform the public about the health risks of excess solar UVR and encourage appropriate sunprotection behaviour.

Several studies have been carried out to assess the impact of the UVI, including on whether the UVI is understood by the public of $\mathrm{NZ}^{[7]}$ and Australia, ${ }^{[8]}$ on the knowledge, awareness and use of the UVI among Australians, ${ }^{[9]}$ on media uptake in response to advocacy and promotion, ${ }^{[5]}$ and in relation to public response in the USA. ${ }^{[10]}$ An early systematic review assessed the effectiveness of using tools such as the UVI in mass media communications and concluded that, while understanding of the UVI seemed to be suboptimal, insufficient research in this area meant that recommendations could not be made. ${ }^{[11]}$ A 2012 systematic review found that, although the UVI is an effective instrument for promoting sun protection, the available evidence suggests that its use has not improved sun-protective practices or reduced sun exposure at the population level. ${ }^{[12]}$

To date, most research has focused on adult knowledge and understanding of the UVI, for example in $\mathrm{NZ}^{[7]}$ and Germany, ${ }^{[13]}$ and also the impact of UVI on adult tanning behaviour in Sweden. ${ }^{[14]}$ Since excess sun exposure in childhood and adolescence is a known risk factor for skin cancer, and because sun-safe practices are most likely to be adopted as part of a healthy sun-exposure lifestyle from a young age, it is important to determine the level of knowledge and understanding of the UVI among school students. The aims of the present investigation were to draw on previously unpublished data from two school-based studies, one in $\mathrm{NZ}^{[15]}$ and the other in $\mathrm{SA},{ }^{[16]}$ to investigate and compare students' knowledge of the UVI and, where possible, report their understanding of this measure. The findings obtained also provide indicative baselines against which any subsequent survey findings could be compared.

\section{Methods}

Both the NZ and SA study methods have been described in detail elsewhere. ${ }^{[15,16]}$ These methods are briefly summarised below, with specific emphasis placed on the UVI sections of the student questionnaires. 


\section{New Zealand study}

Study location and participants. The cross-sectional study was carried out in five provinces at state or state-integrated schools randomly selected from the Ministry of Education schools database. A single class, either year 4 (Y4), modal age 8 years, or year 8 (Y8), modal age 12 years, was randomly selected from each school to participate. Y8 students' results are comparable with grade 7 (G7) (modal age 12 years) students' results in SA.

Questionnaire. The student survey measures assessed sun-related knowledge, attitudes and behaviours. Either four (Y4) or eight (Y8) questions on the UVI assessed both knowledge and understanding of the UVI. The questions on the UVI (Tables 1 and 2) were similar to

Table 1. Student demographics, self-perceived skin photosensitivity and UVI knowledge, with comparisons between NZ Y8 and SA G7 students

\begin{tabular}{|c|c|c|c|c|}
\hline \multirow[b]{2}{*}{ Questionnaire item } & \multicolumn{2}{|c|}{ NZ students } & \multirow[b]{2}{*}{$\begin{array}{l}\text { SA students, G7 }(N=707) \\
n(\%)\end{array}$} & \multirow[b]{2}{*}{$p$-value ${ }^{*}$} \\
\hline & $\begin{array}{l}\text { Y4 (N=214) } \\
n(\%)\end{array}$ & $\begin{array}{l}\text { Y8 }(N=274) \\
n(\%)\end{array}$ & & \\
\hline \multicolumn{5}{|l|}{ Demographics } \\
\hline Age (years) & & & & N/A \\
\hline 7 & $16(7.7)$ & $0(0.0)$ & $0(0.0)$ & \\
\hline 8 & $134(64.7)$ & $0(0.0)$ & $0(0.0)$ & \\
\hline 9 & $53(25.6)$ & $0(0.0)$ & $0(0.0)$ & \\
\hline 10 & $4(1.9)$ & $3(1.1)$ & $0(0.0)$ & \\
\hline 11 & $0(0.0)$ & $55(20.6)$ & $6(0.8)$ & \\
\hline 12 & $0(0.0)$ & $140(52.6)$ & $173(24.5)$ & \\
\hline 13 & $0(0.0)$ & $67(25.1)$ & $429(60.8)$ & \\
\hline Other & $0(0.0)$ & $1(0.3)$ & $97(13.7)$ & \\
\hline Missing data ${ }^{\dagger}$ & 8 & 8 & 2 & \\
\hline \multicolumn{5}{|l|}{ Gender } \\
\hline Male & $106(51.1)$ & $120(45.1)$ & $269(38.3)$ & $>0.001$ \\
\hline Female & $100(48.5)$ & $146(54.9)$ & $434(61.7)$ & \\
\hline Missing data ${ }^{+}$ & 8 & 8 & 4 & \\
\hline \multicolumn{5}{|c|}{$\begin{array}{l}\text { If you went out in the sun without protection in the summer for } \\
30 \text { minutes during the middle of the day, would you: }\end{array}$} \\
\hline Just burn and not tan afterwards & $47(22.7)$ & $55(20.7)$ & $133(18.8)$ & $>0.001$ \\
\hline Burn first, then tan afterwards & $35(16.9)$ & $68(25.6)$ & $151(21.3)$ & \\
\hline Not burn at all, just tan & $54(26.0)$ & $71(26.7)$ & $117(16.5)$ & \\
\hline Don’t know & $71(34.2)$ & $71(26.7)$ & $305(43.2)$ & \\
\hline Missing data ${ }^{\dagger}$ & 7 & 9 & 1 & \\
\hline \multicolumn{5}{|l|}{ Knowledge of UVI } \\
\hline \multicolumn{5}{|l|}{ Have you seen or heard about the UVI? } \\
\hline No & $142(68.9)$ & $113(42.3)$ & $438(61.9)$ & $>0.001$ \\
\hline Yes & $64(31.1)$ & $154(57.7)$ & $269(38.1)$ & \\
\hline Missing data ${ }^{\dagger}$ & 8 & 7 & 0 & \\
\hline Where have you seen or heard about the UVI?ः & & & & N/A \\
\hline Radio & 17 & 27 & 62 & \\
\hline Newspaper & 15 & 35 & 49 & \\
\hline Magazine & 10 & 24 & 66 & \\
\hline People talking about it & 24 & 59 & 83 & \\
\hline At school & 24 & 61 & 111 & \\
\hline Other & 6 & 10 & 21 & \\
\hline Don't know & 19 & 31 & 98 & \\
\hline Total responses & 143 & 319 & 623 & \\
\hline
\end{tabular}


those used in a national survey administered to the general public in $\mathrm{NZ}^{[7]}$ and a survey administered to secondary students, ${ }^{[13]}$ amended post piloting to ensure age-appropriate language. In addition to basic demographic questions, students were also asked to assess their skin photosensitivity by answering the question: 'If you went out in the sun without protection in summer for 30 minutes during the middle of the day, would you: just burn and not tan afterwards; burn first and then tan afterwards; not burn at all, just tan; or don't know. The words 'during the middle of the day' were omitted from the Y4 questionnaire in an attempt to simplify the question for this younger age group.

Procedures. The questionnaire was administered as part of a larger study to measure students' sun exposure. The fourth and the first terms (October 2004 - April 2005), the period during which sun protection is routinely recommended in NZ schools, were chosen for the purpose of measuring sun exposure. Six weeks prior to survey administration, information sheets and consent forms were mailed to class teachers for distribution to parents/guardians. A researcher administered the questionnaire to the class at each school, giving only general instructions to assist completion. Ethical approval was obtained from the University of Otago Human Ethics Committee (Ref. No. 04/028).

\section{South African study}

Study location and participants. A cross-sectional descriptive study was carried out in the nine provinces of SA. Four schools from each province were randomly selected from the Department of Basic Education schools database after ineligible schools (schools without a G7 class, with a class

Table 2. NZ student responses to questions on understanding of, use of and desire to know more about the UVI by year level and gender

\begin{tabular}{|c|c|c|c|c|c|c|c|c|}
\hline \multirow[b]{2}{*}{ Questionnaire item } & \multicolumn{4}{|c|}{ Year 4} & \multicolumn{4}{|c|}{ Year 8} \\
\hline & $\begin{array}{l}\text { All } \\
n(\%)\end{array}$ & $\begin{array}{l}\text { Male } \\
n(\%)\end{array}$ & $\begin{array}{l}\text { Female } \\
n(\%)\end{array}$ & $p$-value & $\begin{array}{l}\text { All } \\
n(\%)\end{array}$ & $\begin{array}{l}\text { Male } \\
n(\%)\end{array}$ & $\begin{array}{l}\text { Female } \\
n(\%)\end{array}$ & $p$-value \\
\hline Would you say the UVI is: & & & & N/A & & & & \\
\hline Easy to understand & - & - & - & & $55(42.6)$ & $23(40.3)$ & $32(39.5)$ & 0.641 \\
\hline Difficult to understand & - & - & - & & $74(57.3)$ & $34(59.6)$ & $49(60.4)$ & \\
\hline Missing data & - & - & - & & 25 & 14 & 11 & \\
\hline \multicolumn{9}{|l|}{$\begin{array}{l}\text { As the number on the UVI gets bigger, it } \\
\text { means the sun's rays are getting stronger: }\end{array}$} \\
\hline Disagree & $7(13.7)$ & $3(8.6)$ & $4(25.0)$ & 0.203 & $8(5.5)$ & $3(4.8)$ & $5(6.1)$ & 0.179 \\
\hline Agree & $32(62.7)$ & $22(62.8)$ & $10(62.5)$ & & $59(41.2)$ & $31(50.0)$ & $28(34.5)$ & \\
\hline Unsure & $12(23.5)$ & $10(28.5)$ & $2(12.5)$ & & $76(53.1)$ & $28(45.1)$ & $48(59.2)$ & \\
\hline Missing data & 13 & 8 & 5 & & 11 & 9 & 2 & \\
\hline $\begin{array}{l}\text { As the number on the UVI gets bigger, it } \\
\text { means you can spend more time in the sun: }\end{array}$ & & & & $\mathrm{N} / \mathrm{A}$ & & & & \\
\hline Disagree & - & - & - & & $80(55.1)$ & $34(56.6)$ & $46(66.6)$ & 0.263 \\
\hline Agree & - & - & - & & $5(3.4)$ & $2(3.3)$ & $2(2.3)$ & \\
\hline Unsure & - & - & - & & $60(41.3)$ & $24(40.0)$ & $36(42.8)$ & \\
\hline Missing data & - & - & - & & 112 & 53 & 59 & \\
\hline $\begin{array}{l}\text { As the number on the UVI gets bigger, } \\
\text { it means that you need to use more sun } \\
\text { protection: }\end{array}$ & & & & $\mathrm{N} / \mathrm{A}$ & & & & \\
\hline Disagree & - & - & - & & $6(4.1)$ & $4(6.25)$ & $2(1.3)$ & 0.487 \\
\hline Agree & - & - & - & & $84(58.3)$ & $35(54.6)$ & $49(34.0)$ & \\
\hline Unsure & - & - & - & & $54(37.5)$ & $25(39.0)$ & $29(20.1)$ & \\
\hline Missing data & - & - & - & & 111 & 51 & 60 & \\
\hline $\begin{array}{l}\text { Family uses the UVI to help them decide } \\
\text { what sun protection to use: }\end{array}$ & & & & N/A & & & & \\
\hline No & - & - & - & & $72(50.0)$ & $30(46.8)$ & $42(52.5)$ & 0.287 \\
\hline Yes & - & - & - & & $14(9.7)$ & $9(14.0)$ & $5(6.2)$ & \\
\hline Unsure & - & - & - & & $58(40.2)$ & $25(39.0)$ & $33(41.3)$ & \\
\hline Missing data & - & - & - & & 104 & 48 & 56 & \\
\hline \multicolumn{9}{|l|}{$\begin{array}{l}\text { Would you like to know more about the } \\
\text { UVI: }\end{array}$} \\
\hline No & $58(28.2)$ & $24(22.8)$ & $34(34.0)$ & 0.077 & $51(19.3)$ & $32(27.1)$ & $19(13.0)$ & 0.004 \\
\hline Yes & $147(71.7)$ & $81(77.1)$ & $66(66.0)$ & & $213(80.6)$ & $86(72.8)$ & 127 (86.9) & \\
\hline Missing data & 1 & 1 & 0 & & 2 & 2 & 0 & \\
\hline
\end{tabular}


size of less than 10, sited in a rural location or where English or Afrikaans were not used for teaching at the school) were removed.

Questionnaire. The questionnaire, provided in both English and Afrikaans, was based on that used in the NZ study, but only one question on the UVI was retained, i.e. 'Have you seen or heard about the UVI?' The other seven questions were not included because it was noted during piloting that most participants did not recall either hearing or seeing anything about the UVI. In addition to basic demographic questions, students were asked to assess their skin photosensitivity by answering the same question as used for Y4 and Y8 students in NZ (see above).

Procedures. The study took place during the third school term between August and October 2012. School principals were invited by telephone to permit their schools to participate and those principals who agreed were couriered questionnaires, information sheets and consent forms, as well as a prepaid courier bag to return completed questionnaires to the researcher. Ethical approval for this study was obtained from the Council for Scientific and Industrial Research (CSIR) Research Ethics Committee (Ref. No. 35/2012).

\section{Statistical analysis}

All analyses were carried out using Stata 13.1 (StataCorp LP, USA). Summary descriptive statistics, including observed frequencies for all variables, were calculated. Statistical significance was assessed using $p<0.05$ for Pearson's $\chi^{2}$ tests with missing data removed.

Table 3. NZ student responses to questions on understanding of, use of and desire to know more about the UVI by year of age

\begin{tabular}{|c|c|c|c|c|c|c|c|c|c|}
\hline Questionnaire item & $\begin{array}{l}7 \text { years } \\
n(\%)\end{array}$ & $\begin{array}{l}8 \text { years } \\
n(\%)\end{array}$ & $\begin{array}{l}9 \text { years } \\
n(\%)\end{array}$ & $\begin{array}{l}10 \text { years } \\
n(\%)\end{array}$ & $\begin{array}{l}11 \text { years } \\
n(\%)\end{array}$ & $\begin{array}{l}12 \text { years } \\
n(\%)\end{array}$ & $\begin{array}{l}13 \text { years } \\
n(\%)\end{array}$ & $\begin{array}{l}\text { Other } \\
n(\%)\end{array}$ & $p$-value \\
\hline \multicolumn{10}{|l|}{ Would you say the UVI is: } \\
\hline Easy to understand & - & - & - & $2(100.0)$ & $12(54.4)$ & $25(35.7)$ & $16(45.7)$ & $0(0.0)$ & 0.140 \\
\hline Difficult to understand & - & - & - & $0(0.0)$ & $10(45.5)$ & $45(64.2)$ & $19(54.2)$ & $0(0.0)$ & \\
\hline Missing data & - & - & - & 3 & 3 & 16 & 6 & 0 & \\
\hline \multicolumn{10}{|c|}{$\begin{array}{l}\text { As the number on the UVI gets } \\
\text { bigger, it means the sun's rays are } \\
\text { getting stronger: }\end{array}$} \\
\hline Disagree & $1(16.6)$ & $3(11.5)$ & $3(15.7)$ & $0(0.0)$ & $0(0.0)$ & $7(8.8)$ & $1(2.5)$ & $0(0.0)$ & 0.046 \\
\hline Agree & $4(66.6)$ & $14(53.8)$ & $14(73.6)$ & 00.0 & $10(41.6)$ & $30(37.9)$ & $19(48.7)$ & $0(0.0)$ & \\
\hline Unsure & $1(16.6)$ & $9(34.6)$ & $2(10.5)$ & $1(100.0)$ & $14(58.3)$ & $42(53.1)$ & $19(48.7)$ & $0(0.0)$ & \\
\hline Missing data & 1 & 7 & 5 & 1 & 1 & 7 & 2 & 0 & \\
\hline \multicolumn{10}{|c|}{$\begin{array}{l}\text { As the number on the UVI gets } \\
\text { bigger, it means you can spend more } \\
\text { time in the sun: }\end{array}$} \\
\hline Disagree & - & - & - & $1(50.0)$ & $14(60.8)$ & $41(51.2)$ & $24(60.0)$ & $0(0.0)$ & 0.862 \\
\hline Agree & - & - & - & $0(0.0)$ & $0(0.0)$ & $3(3.7)$ & $2(5.0)$ & $0(0.0)$ & \\
\hline Unsure & - & - & - & $1(50.0)$ & $9(39.1)$ & $36(45.0)$ & $14(35.0)$ & $0(0.0)$ & \\
\hline Missing data & - & - & - & 4 & 32 & 56 & 22 & 0 & \\
\hline \multicolumn{10}{|c|}{$\begin{array}{l}\text { As the number on the UVI gets } \\
\text { bigger, it means that you need to use } \\
\text { more sun protection: }\end{array}$} \\
\hline Disagree & - & - & - & $0(0.0)$ & $2(8.3)$ & $3(3.7)$ & $1(2.5)$ & $0(0.0)$ & 0.657 \\
\hline Agree & - & - & - & $0(0.0)$ & $12(50.0)$ & $48(60.0)$ & $24(61.5)$ & $0(0.0)$ & \\
\hline Unsure & - & - & - & $1(100.0)$ & $10(41.6)$ & $29(36.2)$ & $14(35.9)$ & $0(0.0)$ & \\
\hline Missing data & - & - & - & 5 & 31 & 55 & 22 & 1 & \\
\hline \multicolumn{10}{|c|}{$\begin{array}{l}\text { Family uses the UVI to help them } \\
\text { decide what sun protection to use: }\end{array}$} \\
\hline No & - & - & - & $0(0.0)$ & $7(29.1)$ & $39(50.0)$ & $26(65.0)$ & $0(0.0)$ & 0.040 \\
\hline Yes & - & - & - & $0(0.0)$ & $5(20.8)$ & $6(7.6)$ & $3(7.5)$ & $0(0.0)$ & \\
\hline Unsure & - & - & - & $2(100.0)$ & $12(50.0)$ & $33(42.3)$ & $11(27.5)$ & $0(0.0)$ & \\
\hline Missing data & - & - & - & 4 & 29 & 53 & 20 & 1 & \\
\hline \multicolumn{10}{|c|}{$\begin{array}{l}\text { Would you like to know more about } \\
\text { the UVI: }\end{array}$} \\
\hline No & $5(31.2)$ & $45(33.8)$ & $7(13.2)$ & $2(33.3)$ & $13(23.6)$ & $26(18.7)$ & $10(15.1)$ & $1(100.0)$ & 0.005 \\
\hline Yes & $11(68.7)$ & $88(66.1)$ & $46(86.7)$ & $4(66.6)$ & $41(76.3)$ & $113(81.2)$ & $56(84.8)$ & $0(0.0)$ & \\
\hline Missing data & 0 & 1 & 0 & 0 & 0 & 1 & 1 & 0 & \\
\hline
\end{tabular}




\section{Results}

\section{Demographics}

For the NZ study, 27 schools participated, 14 of which contributed the 264 Y8 participants and 13 the 214 Y4 participants. A total of 24 schools participated in the SA study and 707 students completed the student questionnaire. Data for a total of 1177 students were included in all analyses (comprising $472 \mathrm{NZ}$ and 705 SA students; students with missing self-reported gender were omitted).

The median age for the NZ Y4 students was 8 years, for the NZ Y8 students it was 12 years, and for the SA G7 students it was 13 years (Table 1). In both the NZ and the SA study, more females than males answered the questionnaire, this ratio being higher in the SA sample.

Students were asked to assess their skin photosensitivity according to the Fitzpatrick Skin Phototype Classification question on burn/ $\tan { }^{[17]}$ Of the NZ Y8 students, there was a relatively even distribution selecting one of the four choices, but with the fewest selecting 'just burn and not tan afterwards' and similar numbers of students selecting the other two options, i.e. 'burn first then tan afterwards' and 'not burn at all just tan'. This was not the case for the NZ Y4 and the SA G7 sample. About one-third of the NZ Y4 students and more than $40 \%$ of the South African students selected 'Don't know' for this question.

\section{Knowledge of the UVI}

More than half of the NZ Y8 sample answered that they had previously heard about or seen the UVI, whereas significantly more SA G7 students and NZ Y4 students replied that they had not seen or heard about the UVI. The largest number of students in both countries who reported having seen or heard about it had done so either via television or at school.

\section{Understanding of the UVI}

The NZ students were asked additional questions to test their understanding of the UVI (Tables 2 and 3). Of the Y8 students completing the question on ease of understanding the UVI, more than half said that it was difficult to understand. Three questions further probed the students' understanding of the UVI and its values. For the statement, 'As the number on the UVI gets bigger, it means the sun's rays are getting stronger', the majority of Y8 students were unsure of their answer, except for Y8 male students, of whom half correctly agreed with this statement. About two-thirds of the Y4 students correctly agreed with this statement, with similar percentages of males and females. Y8 students were asked two additional questions testing their UVI understanding. In both cases, most Y8 students correctly selected the correct response, i.e. they disagreed that 'As the number on the UVI gets bigger, it means you can spend more time in the sun' and agreed that 'As the number on the UVI gets bigger, it means you need to use more sun protection. There were no statistically significant differences by gender for these questions.

One statistically significant difference by self-reported age in years (not year level) was observed for the statement: 'As the number on the UVI gets bigger, it means the sun's rays are getting stronger'; students aged 11,12 and 13 years were more likely than students of other ages to select the 'unsure' response.

\section{Use of the UVI and desire to know more about the UVI}

Y8 students were asked whether or not their family made use of the UVI to help decide which sun protection to use. Only 14 students replied positively, with the majority answering either negatively or indicating that they were unsure. The final question was about whether or not they would like to know more about the UVI, and the majority of the Y4 and Y8 students expressed a desire to know more about the UVI, with slightly more Y8 males than females responding negatively. When asked whether their family utilised the UVI to help them decide what sun protection to use, more 11-year-olds than students of other ages selected 'unsure'.

\section{Discussion}

Few studies have considered the understanding and use of the UVI, with this being the first of which we are aware that focused on primary-school students. The aim of this study was to investigate and compare students' knowledge of the UVI and, where possible, report their understanding of this measure. There is at least some evidence to suggest that some school students have seen or heard of the UVI. However, this is not the case for the majority of students in this study, unlike a study among West Australian adults, aged 18 years and older, that found a high level of awareness and understanding of the UVI. ${ }^{[9]} \mathrm{NZ}$ Y8 students were most likely to have seen or heard of the UVI, perhaps because the UVI has been broadcast and published routinely in some NZ media since 1999, and it may have also been discussed in NZ school curricula. Those students who had seen or heard of the UVI had done so at school or via television. Understanding of general sun exposure and protection also appears to be better in NZ Y8 students, as evidenced by the higher number of Y4 and G7 students reporting their uncertainty regarding what would happen to their skin exposed to the summer sun for 30 minutes.

The UVI was constructed as a simple index using categorical numbers to communicate sun-exposure risk, and sun-protection advice was related to the scale at a later stage. ${ }^{[6]}$ In terms of ease of understanding, when asked whether the UVI was easy or difficult to understand, two-thirds of the students stated that they found the UVI difficult to understand. This may in part explain why the UVI does not appear to change attitudes towards sun protection or sunrelated behaviour, at least for those populations in which ease of UVI understanding has been explored previously. An ICNIRP Working Group decided that changes to the UVI itself were not warranted. ${ }^{[18]}$ However, if a basic comprehension of the UVI metrics is missing, it is unlikely to have a positive influence on sun-related attitudes and behaviours. Teaching about the UVI should begin at school, and this has been the practice in many NZ primary and intermediate schools, although standardised SunSmart Schools curriculum resources, including substantial content about the UVI, were not commissioned and promoted online until 2014. ${ }^{[19]}$

Among the few students who had seen or heard of the UVI, understanding was generally good; most students knew that the increasing UVI numbers meant that the sun's rays were getting stronger and that more sun protection was required. However, a quarter to half of the students were unsure about the appropriate response, suggesting that many are not confident of their understanding of the UVI. Interestingly, younger students tended to agree more readily than their older counterparts with the UVI understanding question.

Despite only 14 students stating that their family used the UVI to help them decide what sun protection to use, most students of all ages and from both countries wanted to know more about the UVI. The UVI categories have been coupled with sun-related behaviour and sun-protection responses. ${ }^{[6]}$ These messages need to be part of the teaching about UVI in schools.

\section{Study limitations}

Study data were collected through the use of self-completed questionnaires. Although the sampling procedures could not ensure representativeness, there is some evidence that neither study sample deviated substantially from the general population of students of the same year and school level. ${ }^{[15,16]}$ The timing of the study was 
the probable reason for the age differences between Y8 and G7 students, since the entire SA survey took place in the second half of the year during the third school term, by which time most students, commencing the year at age 12 , had attained the age of 13 years. In both studies, owing to natural class composition, more females than males, particularly in the SA sample, answered the questionnaire. Some comparability bias may be evident as the different population surveys took place in different years, i.e. in 2004/5 and 2012 for the Y4/Y8 and G7 students, respectively.

\section{Conclusion}

We have demonstrated that awareness and understanding of the UVI among primary school students in two countries are relatively low. While results may not be fully generalisable, they suggest that greater effort is necessary to raise awareness and understanding of the UVI if it is to be promoted as an effective sun-protection tool. The observed lack of awareness among many school students provides an opportunity to introduce an innovative and age-appropriate approach to teaching of the UVI that goes beyond a simple explanation of the metrics. The teaching approach should combine level of risk with behavioural responses to UVI numbers and/or categories and focus on personal relevance of the UVI message. The data presented here further demonstrate that efforts to increase general sun awareness and appreciation of the associated risks are needed in SA for all population groups.

Funding. For the NZ project, Dr Wright received support from the National Research Foundation of South Africa, the National Institute of Water and Atmospheric Research and an International PhD scholarship from the University of Otago. Dr Wright was employed by the Council of Scientific and Industrial Research when the SA study was carried out. Dr Reeder and the Cancer Society Social and Behavioural Research Unit received funding from the Cancer Society of New Zealand Inc. and the University of Otago. Funding for the SA project was granted in part by the Cancer Association of South Africa, the Council for Scientific and Industrial Research and the Medical Research Council of South Africa. Acknowledgements. Sincere thanks go to all the school principals, teachers and students who participated in both studies; to Nathalie
Huston and Jan Jopson (NZ), and Nelvia Phala and Lesley Wright (SA) for assistance with project administration and co-ordination.

\section{References}

1. Dennis LK, Vanbeek MJ, Beane Freeman LE, Smith BJ, Dawson DV, Coughlin JA. Sunburns and risk of cutaneous melanoma: Does age matter? A comprehensive meta-analysis. Ann Epidemiol 2008;18(8):614-627. [http://dx.doi.org/10.1016/j.annepidem.2008.04.006]

2. Green AC, Wallingford SC, McBride P. Childhood exposure to ultraviolet radiation and harmful skin effects: Epidemiological evidence. Prog Biophys Mol Biol 2011;107(3):349-355. [http://dx.doi. org/10.1016/j.pbiomolbio.2011.08.010]

3. IARC Globocan. 2012. Melanoma of the skin ASR (W) per 100,00, all ages. http://globocan.iarc.fr/old/ bar_sex_site.asp?selection $=16120 \&$ title $=$ Melanoma + of + skin\&statistic $=2 \&$ populations $=5 \&$ window bar_sex_site.asp? 3 selection $=16120 \&$ title $=$ Melanoma + of + skin\&statistic $=2 \&$ populations $=5 \&$ window
$=1$ grid $=1 \&$ info $=1 \&$ color $1=5 \&$ color $1 \mathrm{e}=\&$ color $2=4 \&$ color $2 \mathrm{e}=\&$ submit $=\% \mathrm{C} 2 \% \mathrm{~A} 0$ Execute $\% \mathrm{C} 2 \% \mathrm{~A} 0$ $=1 \&$ grid $=1 \&$ info $=1 \&$ col
(accessed 20 May 2015).

4. Norval M, Kellet P, Wright CY. The incidence and body site of skin cancers in the population groups of South Africa. Photodermatol Photoimmunol Photomed 2014;30(5):262-265. [http://dx.doi. of South Africa. Photoder
org $/ 10.1111 /$ phpp.12106]

5. Richards R, Reeder AI, Bulliard J-L. Fine forecasts: Encouraging the media to include ultraviolet radiation information in summertime weather forecasts. Health Educ Res 2004;19(6):677-685. [http:// dx.doi.org/10.1093/her/cyg085]

6. World Health Organization. Global Solar UV Index: A Practical Guide. A joint recommendation of the World Health Organization, the World Meteorological Organization, the United Nations Environment Programme and the International Commission on Non-Ionizing Radiation Protection. 2002. http:// www.who.int/uv/publications/en/UVIGuide.pdf (accessed 20 January 2015).

7. Bulliard J-L, Reeder AI. Getting the message across: Sun protection information in media weather reports in New Zealand. N Z Med J 2001;114(1126):67-70.

8. Carter OBJ, Donovan RJ. Public (mis)understanding of the UV Index. J Health Commun 2007;12(1):41-52. [http://dx.doi.org/10.1080/10810730601093371]

9. Blunden A, Lower T, Slevin T. Knowledge, awareness and use of the UV Index amongst the West Australian 9. Blunden A, Lower T,Slevin T. Knowledge, awareness and use ofthe UV Indexamongst the West Au
public. J Health Commun 2004:9(3):207-221. [http://dx.doi.org/10.1080/10810730490447057]

public. J Health Commun 2004:9(3):207-221. [http://dx.doi.org/10.1080/10810730490447057]
10. Geller AC, Hufford D, Miller DR, et al. Evaluation of the Ultraviolet Index: Media reactions and public 0. Geller AC, Hufford D, Miller DR, et al. Evaluation of the Ultraviolet Index: Media reactions and public
response. J Am Acad Dermatol 1997;37(6):935-941. [httt://dx.doi.org/10.1016/S0190-9622(97)70068-9]

11. Saraiya M, Glanz K, Briss PA, et al. Interventions to prevent skin cancer by reducing exposure to ultraviolet radiation: A systematic review. Am J Prev Med 2004;27(5):422-466. [http://dx.doi.org/10.1016/j.amepre.2004.08.009]

12. Italia N, Rehfuess EA. Is the Global Solar UV Index an effective instrument for promoting sun protection: A systematic review. Health Educ Res 2012;27(2):200-213. [http://dx.doi.org/10.1093/her/cyr050]

13. Jopson J, Reeder AI. Sun Protection in New Zealand Secondary Schools: Obstacles and Opportunities. Dunedin: University of Otago, 2004. Available from AI Reeder, tony.reeder@otago.ac.nz

14. Bränström R, Ullen $\mathrm{H}$, Brandberg $\mathrm{Y}$. A randomised population-based intervention to examine the effects of the ultraviolet index on tanning behaviour. Eur J Cancer 2003;39(7):968-974. [http://dx.doi. org/10.1016/S0959-8049(03)00117-5]

15. Wright C, Reeder A, Bodeker G, Gray A, Cox B. Solar UVR exposure concurrent activities and sun-protective practices among primary schoolchildren. Photochem Photobiol 2007;83(3):749-758. [http://dx.doi.org/10.1562/2006-08-22-RA-1010]

16. Wright CY, Albers PN, Oosthuizen MA, Phala N. Self-reported sun-related knowledge, attitudes and behaviours among schoolchildren attending South African primary schools. Photodermatol Photoimmunol Photomed 2014;30(5):226-276. [http://dx.doi.org/10.1111/phpp.12107]

17. Fitzpatrick TB. The validity and practicality of sun-reactive skin types I through IV. Arch Dermatol 1988;124(6):869-871. [http://dx.doi.org/10.1001/archderm.1988.01670060015008]

18. Allinson S, Asmuss M, Baldermann C, et al. Validity and use of the UV Index: Report from the UVI Working Group, Schloss Hohenkammer, Germany, 5 - 7 December 2011. Health Physics 2012;103(3):301-306. [http://dx.doi.org/10.1097/HP0b013e31825b581e]

19. Cancer Society. Curriculum Resources for Level 1, Level 2, Level 3 and Level 4. 2015. http://www. sunsmartschools.co.nz/teachers/curriculum-resources (accessed 20 May 2015).

Accepted 5 October 2015. 